Report

\title{
EGFR and EGFRvIII expression in primary breast cancer and cell lines
}

\author{
James M. Rae ${ }^{1}$, Joshua O. Scheys ${ }^{1}$, Kim M. Clark ${ }^{2}$, Robert B. Chadwick ${ }^{2}$, Michael C. \\ Kiefer $^{2}$, and Marc E. Lippman ${ }^{1}$ \\ ${ }^{1}$ Department of Internal Medicine, Division of Hematology Oncology, University of Michigan Medical \\ Center, Ann Arbor, MI; ${ }^{2}$ Genomic Health Inc., Redwood City, CA, USA
}

Key words: breast cancer, clinical, EGFRvIII, epidermal growth factor receptor, expression

\begin{abstract}
Summary
EGFRvIII is a constitutively activated truncated variant of the epidermal growth factor receptor (EGFR) which has been shown to increase tumorgenicity. There are conflicting reports on the extent of EGFRvIII expression in tissues which may in part stem from the use of different assay methodologies. We investigated the expression of both EGFRvIII and wild-type EGFR (EGFRwt) in cell lines and primary breast cancers. First, we used a RT-PCR assay that can simultaneously measure EGFRwt and EGFRvIII mRNA to screen 55 tumor cell lines. We show that except for EGFRvIII transfected cells, only EGFRwt was detected. We then validated a real-time PCR assay and used this to screen 170 formalin fixed paraffinembedded primary breast cancers for evidence of EGFRwt and EGFRvIII expression. No samples were positive for EGFRvIII expression except for control transfectants and glioblastomas. In contrast, EGFRwt was expressed at varying levels in the majority of samples tested. We conclude that the expression of EGFRvIII is extremely rare in breast cancer and therefore it does not contribute to the malignant phenotype.
\end{abstract}

Abbreviations: CYP: cyclophilin; EGFR: epidermal growth factor receptor; EGFRvIII: epidermal growth factor receptor variant III; FPET: formalin fixed paraffin-embedded tissue; GAPDH: glyceraldehyde-3phosphate dehydrogenase

\section{Introduction}

The epidermal growth factor receptor (EGFR) is a $170 \mathrm{kd}$ transmembrane protein which exhibits intrinsic tyrosine kinase activity following the binding of one of its cognate ligands. Activation of EGFR leads to many cellular responses including mitogenesis and cellular proliferation [1]. Overexpression and/or amplification of EGFR has been found in many human tumors including, gastric, esophageal, breast, prostate, glioblastoma and lung, and has been associated with poor prognosis [2]. These factors make EGFR an attractive target for tumor specific therapies and several com- pounds aimed at inhibiting EGFR signaling are now in clinical trials [3]. However, this receptor is also expressed in many normal tissues including the liver and skin and therefore drugs designed to disrupt EGFR activity could have severe side affects. Therefore, targeting growth factor receptors with more restrictive expression in tumors but not normal tissues would, in theory, be less likely to cause side effects. A potential tumor specific growth receptor may be EGFRvIII. This receptor is a mutant or variant form of the EGFR which contains an 801-bp in-frame deletion that lacks exons 2-7 resulting in the production of a constitutively active truncated receptor without the 
traditional ligand binding domain [4-6]. This form of the receptor was originally discovered in a glioblastoma and subsequent studies suggested that it is also expressed in breast and non-small cell lung carcinomas but not in normal tissues [7-9]. In contrast, a recent publication using antibodies tested for specificity towards wild-type EGFR (EGFRwt) and EGFRvIII was unable to detect the variant in any tumors outside the brain [10]. Most of these studies relied on immunohistochemical techniques to examine EGFRvIII expression. Unfortunately, the antibodies used may cross-react with other proteins including EGFRwt and may produce equivocal results.

Although detection of EGFRvIII mRNA is not conclusive proof of protein expression, the absence of the message would rule out expression. Two published reports where RT-PCR was used to measure EGFRvIII and wild-type EGFR message in a small number of primary breast cancers specimens have produced conflicting results. The results by $\mathrm{Ge}$ et al. [9] suggest that EGFRvIII is expressed in the majority of primary breast cancers $(19 / 28)$ while Tidow et al. [11] were unable to detect this variant form of EGFR in any of the 23 primary breast cancers analyzed. We set out to definitively answer this question by examining EGFRvIII expression at the RNA level in a comprehensive panel of breast cancer cell lines and 153 cases of invasive ductal carcinoma and 17 cases of invasive lobular carcinoma, using RT-PCR and a validated specific and sensitive real-time PCR assay. We chose to look at breast cancer in order to determine the potential of EGFRvIII as a therapeutic target and to attempt to clarify the inconsistency in the literature.

\section{Materials and methods}

\section{Cell lines and culture conditions}

Tumor cell lines were originally obtained from the Lombardi Cancer Center Tissue Culture Shared Resource at Georgetown University (Washington, DC) and maintained at $37^{\circ} \mathrm{C}$ in a $5 \% \mathrm{CO}_{2}$ atmosphere in improved minimal essential medium (Biosource International, CA) supplemented with $10 \%$ fetal bovine serum (Valley Biomedical Products, VA).

\section{Paraffin-embedding cell lines}

In order to validate our real-time PCR assays we formalin fixed, paraffin embedded tumor cells with varying expression levels of EGFRwt and EGFRvIII. The controls for EGFRwt mRNA expression included MDA MB 468 (high expression), MCF-7 (low expression), MDA MB 435 (undetectable) cells, none of which express EGFRvIII. The positive controls for EGFRvIII included MCF-7 breast cancer cells transfected with an EGFRvIII expression construct (MCF-7/EGFRvIII) as described previously [12]. For additional controls, we purchased formalin fixed, paraffin-embedded glioblastoma samples from Clinomics Biosciences Inc. (Pittsfield, MA). Cell lines were trypsinized, centrifuged, washed with $1 \times$ PBS and $\sim 10^{6}$ cells were added to $15 \mathrm{ml}$ tubes. Next the cells were suspended in $500 \mu$ of freshly prepared bovine plasma (Sigma \# P-4639) and clot formation initiated by adding $100 \mu \mathrm{l}$ of $1000 \mathrm{U} / \mathrm{ml}$ Thrombin (Sigma \# T-4648). After $10 \mathrm{~min}$ incubation at room temperature, cell pellets were formalin fixed in $10 \%$ buffered formalin for several hours and then paraffin-embedded.

\section{Primary breast cancer specimens}

A total 170 primary breast cancers were examined which included 153 invasive ductal carcinomas and 17 invasive lobular carcinomas. The specimens were obtained in a research protocol approved by the Providence Saint Joseph Medical Center, Burbank, CA. Surgery was performed between 1990 and 1997. One 5- $\mu \mathrm{m}$ section from the most representative block was stained by $H \& E$ and confirmed by histopathology to contain invasive breast carcinoma. The RNA was extracted from three $10-\mu \mathrm{m}$ sections of the most representative block, without dissection.

\section{$R N A$ isolation}

Total RNA from cell lines was isolated from tumor cells using Trizol Reagent (Invitrogen, CA). Yield and quality were determined by spectrophotometry (Beckman DU ${ }^{\circledR}$ 640, Beckman Coulter, Inc., Fullerton, CA) and using a Bioanalyzer RNA 6000 Nano chip (Agilent Technologies, Palo Alto, CA). All samples were stored at $-80{ }^{\circ} \mathrm{C}$. Total RNA was extracted from formalin fixed 
paraffin embedded cell lines $\left(\sim 10^{4}-10^{5}\right.$ cells $)$ and tissue samples $(3-6,10 \mu \mathrm{m}$ sections) using the MasterPure $^{\mathrm{TM}}$ RNA Purification Kit (Epicentre Madison, WI) according to the manufacturer's instructions. The recovered RNA pellet was washed twice with $1 \mathrm{ml} 75 \%$ ethanol and resuspended in $30 \mu \mathrm{l}$ nuclease-free water. All samples were DNase treated and assayed for residual genomic DNA using the real-time PCR assay for $\beta$-actin as described below. The yield of total RNA for FPET primary breast cancer specimens was $3.9 \pm 3.0 \mu \mathrm{g}$ (mean $\pm \mathrm{SD}, n=170$ ).

\section{$R T-P C R$}

Random primers were used to reverse transcribe $1 \mu \mathrm{g}$ total RNA from cell lines using the Reverse Transcription System (Promega, Madison, WI) and resulting cDNA diluted to a total of $100 \mu \mathrm{l}$ in TE buffer $\mathrm{pH}$ 8.0. PCR was performed using an iCycler Thermal Cycler (Bio-Rad, Hercules, CA). A $50 \mu 1$ reaction containing $5 \mu \mathrm{l}$ cDNA, $45 \mu 1$ Platinum PCR Supermix (Invitrogen, CA) and $250 \mathrm{nM}$ of each primer was run using the following cycle conditions: $3 \mathrm{~min}$ denaturing at $94{ }^{\circ} \mathrm{C}$ followed by 35 cycles of $94{ }^{\circ} \mathrm{C}$ for $45 \mathrm{~s}, 60^{\circ} \mathrm{C}$ for $45 \mathrm{~s}$, and $72{ }^{\circ} \mathrm{C}$ for $2 \mathrm{~min}$ followed by a final $72{ }^{\circ} \mathrm{C}$ incubation for $7 \mathrm{~min}$. We used the same primer sequenced described by Luo et al. [13] and Ge et al. [9] and purchased the oligonucleotides from Integrated DNA Technologies, Inc. (Coralville, IA) with forward primer sequence $5^{\prime}$-ATG CGA CCC TCC GGG ACG-3' and reverse sequence $5^{\prime}$-GAG TAT GTG TGA AGG AGT-3'. As a control for RNA loading, we amplified human GAPDH using the forward primer 5'-GAA GGT GAA GGT CGG AGT C- $3^{\prime}$ and reverse $5^{\prime}$-GAA GAT GGT GAT GGG ATT TC- $3^{\prime}$. The cycle conditions were: denaturing at $94{ }^{\circ} \mathrm{C}$ for $2 \mathrm{~min}$ followed by 35 cycles of $94{ }^{\circ} \mathrm{C}$ for $30 \mathrm{~s}, 55^{\circ} \mathrm{C}$ for $30 \mathrm{~s}$, and $72{ }^{\circ} \mathrm{C}$ for $30 \mathrm{~s}$ followed by a final $72{ }^{\circ} \mathrm{C}$ incubation for $5 \mathrm{~min}$. The RT-PCR products were resolved on a $2 \%$ agarose gel (Invitrogen, CA), stained with SYBR $^{\circledR}$ Green 1 (Molecular probes, OR) and visualized using an EDAS 290 Camera (Eastman Kodak Company, NY).

\section{Genomic DNA detection}

Prior to real-time PCR analysis, RNA extracts from formalin fixed paraffin embedded samples were tested for the presence of residual genomic DNA (gDNA). Primers and a dual labeled fluorogenic probe were used to detect $\beta$-actin. The primers were forward 5'-CAG CAG ATG TGG ATC AGC AAG-3', reverse 5'-GCA TTT GCG GTG GAC GAT-3' and internal probe 5'-FAMAGG AGT ATG ACG AGT CCG GCC CCBHQ1-3'C. PCR was carried out with the Taqman ${ }^{\circledR}$ Universal PCR Master Mix, without AmpErase UNG (ABI, Foster City, CA). The cycle conditions were: denaturing at $94{ }^{\circ} \mathrm{C}$ for $10 \mathrm{~min}$. followed by 40 cycles of $95^{\circ} \mathrm{C}$ for $20 \mathrm{~s}, 60^{\circ} \mathrm{C}$ for $45 \mathrm{~s}$. Reactions were performed in a $5 \mu$ reaction on an ABI PRISM ${ }^{\circledR} 7900$ HT Detection System. Since there was no reverse transcription step, any signal generated must be from residual gDNA. If any samples generated a threshold PCR amplification cycle time $\left(C_{\mathrm{T}}\right.$ value) of 36 (with threshold set at 0.2 ) or lower in this assay, it was re-DNase treated until the signal from this assay was above a $C_{\mathrm{T}}$ value of 36 (with threshold set at 0.2 ).

\section{Real-time $R T$-PCR}

Expression of EGFRwt, EGFRvIII as well as two reference normalization genes, glyceraldehyde-3phosphate dehydrogenase (GAPDH), and cyclophilin (CYP), were measured in paraffin-embedded samples by a two-step real-time RT-PCR method using the TaqMan ${ }^{\circledR}$ Universal PCR Master Mix, without AmpErase UNG (ABI, Foster City, CA). Copy DNA (cDNA) was generated using the SuperScript First Strand Synthesis System for RTPCR (Invitrogen, CA). Briefly, 100-500 ng total RNA was reverse-transcribed using $50 \mu \mathrm{m}$ random hexamers, $1 \mu \mathrm{M}$ of each gene specific primer (see below), $25 \mathrm{mM} \mathrm{MgCl} 2,10 \mathrm{mM}$ dNTPs, $0.1 \mathrm{M}$ DTT and 50 units Superscript II. The RT-PCR reaction was incubated in a MJ Thermocycler (MJ Research Inc., MA) under the following conditions: $42{ }^{\circ} \mathrm{C}$ for $2 \mathrm{~min}, 25^{\circ} \mathrm{C}$ for $10 \mathrm{~min}, 42^{\circ} \mathrm{C}$ for $50 \mathrm{~min}$ and $70^{\circ} \mathrm{C}$ for $15 \mathrm{~min}$. The first strand cDNA was then used as a template for the TaqMan assay (1 ng RNA equivalent per well per plate). Sequences for the primers and probes were generated using either Primer Express (ABI, Foster City, CA) or Primer 3 software (http:// www-genome.wi.mit.edu/cgi-bin/primer/primer3 www.cgi). The specificity of the primer and probe sequences were confirmed by the UCSC Genome Bioinformatics BLAT program (http://genome. 
ucsc.edu/cgi-bin/hgBlat?command $=$ start \& org $=$ human). The primers used were as follows: EGFRvIII forward 5'-GAG TCG GGC TCT GGA GGA AAA G-3', reverse 5'-CCA CAG GCT CGG ACG CAC-3' and internal probe 5'-FAMAGC CGT GAT CTG TCA CCA CAT AAT TAC C-BHQ1-3'; EGFRwt forward 5'-TGT CGA TGG ACT TCC AGA AC-3', reverse 5'-ATT GGG ACA GCT TGG ATC A-3' and internal probe 5'-FAM-CAC CTG GGC AGC TGC CAA-BHQ1-3'; GAPDH forward 5'-ATT CCA CCC ATG GCA AAT TC-3', reverse 5'-GAT GGG ATT TCC ATT GAT GAC A-3' and internal probe 5'-FAM-CCG TTC TCA GCC TTG ACG GTG C-BHQ1-3'; CYP forward 5'TGG ACT TCT AGT GAT GAG AAA GAT TGA-3', reverse 5'-CAC TGC GAG ATC ACC ACA GGT A-3' and internal probe 5'-FAM-TTC CCA CAG GCC CCA ACA ATA AGC C-BHQ1- $3^{\prime}$. Cycling was performed as for the gDNA detection assay.

\section{Results}

We wanted to determine the incidence of EGFRvIII expression in breast cancer in order to evaluate its potential as a target for tumor specific cancer therapies. We began by screening 55 tumor cell lines for EGFRvIII expression using a reverse transcriptase polymerase chain reaction (RT-PCR) assay that can simultaneously detect both the EGFRwt and EGFRvIII mRNA. As a positive control for EGFRvIII expression we isolated RNA from MCF-7 breast cancer cells transfected with an EGFRvIII expression construct (MCF-7/ EGFRvIII) as described previously [12]. The RTPCR products were separated on $2 \%$ agarose gels. The EGFRwt and EGFRvIII produced a 1153-

(a)

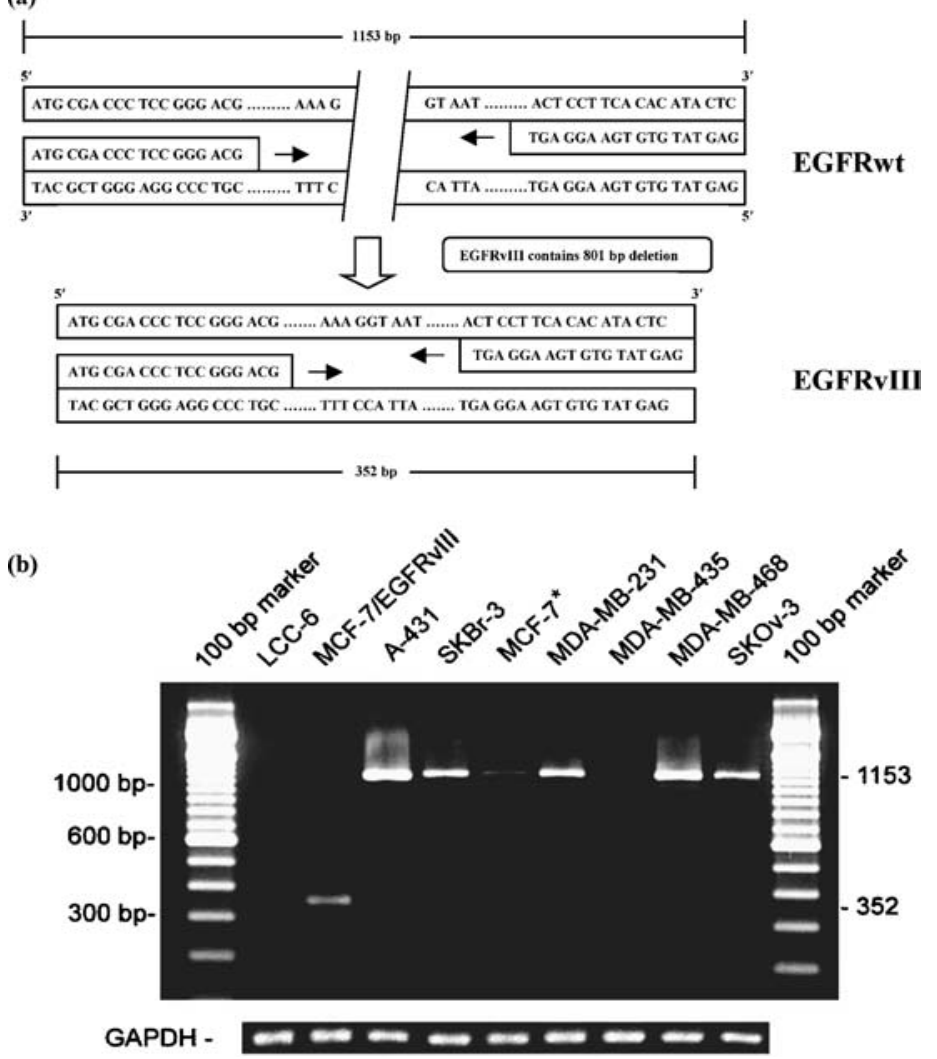

Figure 1. Analysis of EGFRwt and EGFRvIII mRNA expression in a panel of breast cancer cell lines by reverse-transcription polymerase chain reaction (RT-PCR). Total RNA was extracted from 9 cell lines, reverse transcribed and PCR amplified using primers flanking the deleted region in EGFRvIII (a). MCF-7 cells transfected with EGFRvIII cDNA were used as a positive control. Products were resolved on a $2 \%$ gel and stained with SYBR ${ }^{\circledR}$ Green 1 . The EGFRwt produces a 1153-bp product while the EGFRvIII produces a smaller 352-bp product. GAPDH is shown as a control for RNA (b). * A faint but clearly visible 1153-bp band in the column labeled MCF-7 was lost when the image was formatted for publication. 
Table 1. Fifty five cell lines were screened for EGFRwt and EGFRvIII expression by RT-PCR

\begin{tabular}{|c|c|c|c|}
\hline Cell line & Tumor type & EGFRwt & EGFRvIII \\
\hline MCF-7vIII & Breast & \pm & ++ \\
\hline MCF-7 & Breast & + & - \\
\hline MDA MB 468 & Breast & ++++ & - \\
\hline MDA MB 231 & Breast & +++ & - \\
\hline SKBr-3 & Breast & ++ & - \\
\hline SKOV-3 & Ovarian & ++ & - \\
\hline MDA MB 435 & Melanoma & - & - \\
\hline LCC-6 & Melanoma & - & - \\
\hline SW-620 & Colorectal & + & - \\
\hline LS-174T & Colorectal & \pm & - \\
\hline HepG2 & Hepatocellular & \pm & - \\
\hline Нер3В & Hepatocellular & + & - \\
\hline A-431 & Epidermoid & ++++ & - \\
\hline \multicolumn{4}{|c|}{ UCSF interspore breast cancer cells } \\
\hline HCC-202 & Breast & +++ & - \\
\hline HCC-38 & Breast & ++ & - \\
\hline HBL-100 & Breast & ++ & - \\
\hline DU-4475 & Breast & - & - \\
\hline BT-549 & Breast & ++ & - \\
\hline BT- 483 & Breast & \pm & - \\
\hline BT-474 & Breast & + & - \\
\hline BT-20 & Breast & ++++ & - \\
\hline 600-MPE & Breast & + & - \\
\hline HCC-3153 & Breast & ++ & - \\
\hline HCC-2185 & Breast & +++ & - \\
\hline HCC-2157 & Breast & \pm & - \\
\hline HCC-1954 & Breast & +++ & - \\
\hline HCC-1937 & Breast & +++ & - \\
\hline HCC-1569 & Breast & + & - \\
\hline HCC-1428 & Breast & + & - \\
\hline HCC-1143 & Breast & ++ & - \\
\hline HCC-1007 & Breast & - & - \\
\hline MDA MB 435 & Melanoma & - & - \\
\hline MDA MB 415 & Breast & - & - \\
\hline MDA MB 361 & Breast & ++ & - \\
\hline MDA MB 231 & Breast & +++ & - \\
\hline MDA MB $134 \mathrm{VI}$ & Breast & - & - \\
\hline MDA MB 157 & Breast & ++ & - \\
\hline MCF-7 & Breast & + & - \\
\hline LY-2 & Breast & ++ & - \\
\hline HS-578T & Breast & +++ & - \\
\hline SUM-185 & Breast & - & - \\
\hline SUM-159 & Breast & ++ & - \\
\hline SUM-149 & Breast & ++ & - \\
\hline SUM-52 & Breast & - & - \\
\hline SUM-44 & Breast & - & $\begin{array}{l}- \\
\text { (Continued }\end{array}$ \\
\hline
\end{tabular}


Table 1. (Continued)

\begin{tabular}{llll}
\hline Cell line & Tumor type & EGFRwt & EGFRvIII \\
\hline SKBr-3 & Breast & ++ & - \\
MDA MB 468 & Breast & ++++ & - \\
MDA MB 453 & Breast & - & - \\
MDA MB 436 & Breast & +++ & - \\
ZR 75-30 & Breast & - & - \\
ZR 75-B & Breast & - & - \\
ZR 75-1 & Breast & ++ & - \\
T-47D & Breast & + & - \\
SUM-1315 & Breast & +++ & - \\
SUM-190 & Breast & + & - \\
\hline
\end{tabular}

Five breast, 1 ovarian, 2 melanoma, 2 colorectal, 2 hepatocellular and 1 epidermoid cancer cell lines were cultured from frozen stocks, RNA was extracted and assayed along with RNA extracts from an additional 42 breast cancer cell lines obtained from the UCSF Interspore shared resource. No expression is indicated with a $(-)$ and positive expression is shown qualitatively with $( \pm)$ representing barely detectable up to $(++++)$ representing high mRNA expression.

and 352-bp band, respectively as shown schematically in Figure 1(a). Only the MCF-7 cells transfected with the EGFRvIII construct expressed EGFRvIII while EGFRwt was expressed at variable levels in the majority of cells as shown in Figure 1(b). These results were confirmed by repeating all assays at least three times. Also shown are the RT-PCR products for GAPDH as a control for RNA integrity and loading. Using this method, we assayed 5 breast, 1 ovarian, 2 mela- noma, 2 colorectal, 2 hepatocellular and 1 epidermoid cancer cell lines. EGFRvIII was not detected in any of these cells while EGFRwt was found to be expressed at varying levels in all cells except for the MDA MB 435 cells and LCC-6, a variant of that line.

We were unable to detect endogenous EGFRvIII expression in our initial screen which contained only a small number of breast cancer cell lines. Therefore, to better characterize its

(a)

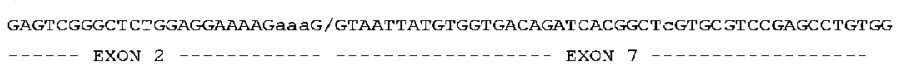

(b)

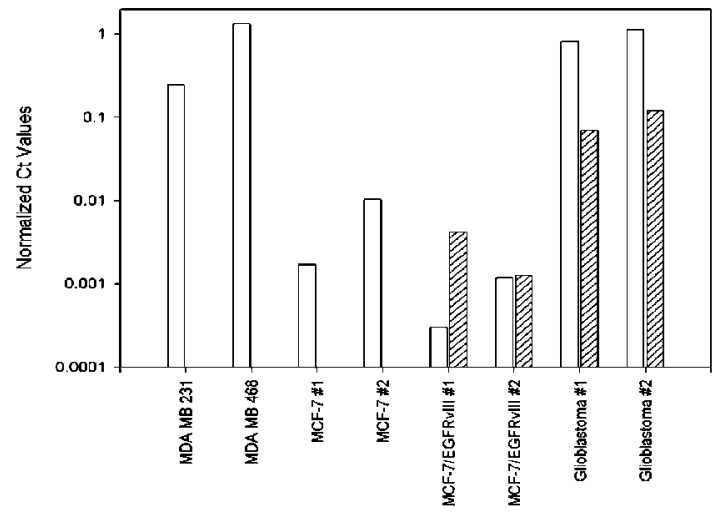

Figure 2. Real-time RT-PCR analysis of EGFRwt and EGFRvIII expression in RNA extracted from formalin fixed paraffinembedded tumor cell lines. Cell pellets were made from cultured tumor cell lines then formalin fixed and paraffin embedded. Samples were sectioned, RNA isolated, and mRNA levels determined by real-time RT-PCR analysis as described in the materials and methods section. Shown are the normalized fold expression levels of EGFRwt (open bars) and EGFRvIII (filled bars) each normalized to the same two housekeeping genes. GAPDH and CYP, and represents the mean of triplicates determinations. 
expression we obtained RNA samples from 42 breast cancer cell lines from the University of California San Francisco InterSpore cell repository where a collection of breast cancer cells lines from various institutions are maintained. Again not a single cell line was found to express EGFRvIII while variable expression of EGFRwt was detected in the majority of samples. The results from all the cell lines are shown in Table 1 where the grading system used for expression ranges from undetectable (-) to high expression $(++++)$.

Tumor cells grown in vitro must undergo adaptive changes in order to survive tissue culture conditions and therefore, the absence of detectable EGFRvIII in tissue culture cells might be an in vitro artifact and not truly represent the in vivo expression. To test this hypothesis, we used realtime RT-PCR to measure EGFRwt and EGFRvIII in 170 formalin fixed paraffin embedded primary breast cancers. We chose real-time RTPCR because it is more reliable as a quantitative assay than other RT-PCR methods. Primers and a fluorogenic probe where designed across the exon 2/exon 7 breakpoint as shown in Figure 2(a) (sequence of primers and probe are shown as capital letters). This Taqman assay was first tested on a synthetic template and four glioblastoma formalin fixed paraffin embedded samples (data not shown). This assay gave a reliable signal when an

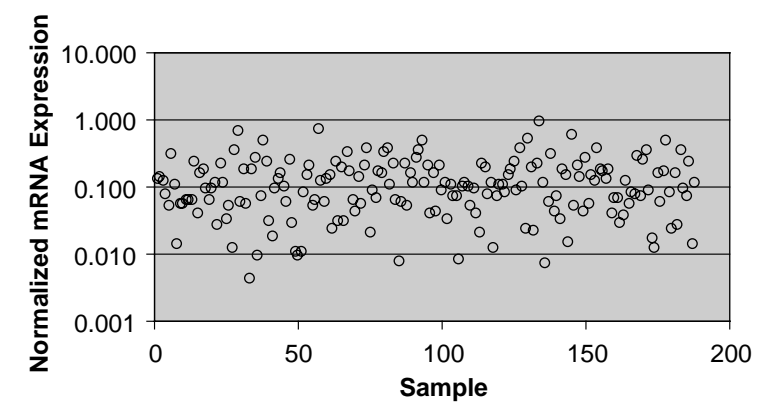

Figure 3. EGFRwt expression in 170 primary breast cancers. Real-time RT-PCR was used to examine EGFRwt and EGFRvIII expression in formalin fixed paraffin embedded primary breast cancers. The samples were sectioned, RNA isolated, DNase treated, assayed for gDNA contamination then screened for mRNA expression by real-time RT-PCR analysis as described in the materials and methods section. Since all samples were negative for EGFRvIII ( $C_{\mathrm{T}}$ values of 40 ), only the results for EGFRwt are shown. Shown are the mean $C_{\mathrm{T}}$ values normalized to two reference normalization genes (duplicates determinations).
EGFRvIII synthetic template was used in the reaction. Out of the four glioblastoma samples investigated, two were positive for the presence of EGFRvIII and two were negative for the variant. It was determined that the assay could reproducibly detect the synthetic template down to approximately 10 copies per reaction mix. It was also able to detect the presence of EGFRvIII in the two positive glioblastoma samples from as little as $0.05 \mathrm{ng}$ input RNA per assay well.

To further test sensitivity and specificity of our real-time PCR assay we had cell pellets from several tumor cell lines, including cells transfected with an EGFRvIII expression construct, formalin fixed and paraffin embedded. The samples were then sectioned and RNA was isolated as described in the materials and methods section. The extracts were assayed in a blinded fashion, for both EGFRwt and EGFRvIII mRNA expression and normalized to two reference normalization genes (GAPDH and CYP). The $C_{\mathrm{T}}$ values are plotted in Figure 2(b). Included in the assay were the two glioblastoma samples previously testing positive for EGFvIII mRNA expression. In addition, we analyzed RNA extracted from two separate MCF-7 and MCF-7/EGFRvIII cell pellets which were processed on separate days and formalin fixed over different periods of time (1-7 days). Shown in the open bars are the normalized $C_{\mathrm{T}}$ values for EGFRwt while the filled bars represent the variant EGFRvIII. The expression of EGFRwt varied considerably but was detected in all samples except for the MDA MB 435 cells (not plotted). The expression of EGFRvIII was readily detectable in the MCF-7/EGFRvIII transfectants and glioblastoma samples but not in any of the breast cancer cell lines including the MDA MB 435 cells.

Having validated the real-time RT-PCR for sensitivity and specificity, we then screened a total of 170 primary breast cancers for EGFRwt and EGFRvIII. The samples included 153 invasive ductal carcinomas and 17 invasive lobular carcinomas collected between 1990 and 1997. To control for RNA quality, the expression of EGFRwt and EGFRvIII was normalized to two reference normalization genes as described above. As shown in Figure 3, in these samples the normalized expression levels of EGFRwt varied over a three log range. Despite being able to readily detect EGFRwt and the reference normalization genes, 
we were unable to detect the expression of EGFRvIII in any of these samples.

\section{Discussion}

In this study we were unable to detect measurable levels of EGFRvIII expression in any tumor cell line or primary breast cancer RNA, despite being able to detect a wide range of EGFRwt expression. Our results are consistent with the recent paper from Jungbluth et al. who, using immunohistochemistry with well characterized antibodies for EGFRwt and EGFRvIII, show that EGFRvIII was undetectable in 10 out of 10 breast primary cancers [10]. These results are in contrast to those published by other investigators who have found EGFRvIII protein in primary breast cancers as well as in other cancers [7-9]. These conflicting reports may reflect differences in the antibodies or protocols used for immunohistochemical staining in these studies. To avoid this issue, we chose to measure mRNA levels using rigorously tested and controlled RT-PCR and real-time PCR assays. Our results are consistent with those of Tidow et al. who were unable to detect EGFRvIII mRNA in any of their 23 primary breast cancers, results which were confirmed by Western blot analysis [11]. These findings along with ours are in contrast to those of Ge et al. who used RT-PCR as well as immunohistochemistry to detect EGFRvIII in primary breast cancer [9]. Their results showed that $67.8 \%$ $(19 / 28)$ of primary breast cancers had detectable levels of EGFRvIII mRNA and 57.8\% (11/19) were positive for protein expression by immunohistochemical staining. There are several reasons for these conflicting results. One possibility is sampling bias, which seems unlikely because of the large number $(n=170)$ of primary breast tumors assayed by our group and the 23 samples assayed by Tidow et al. Furthermore, Ge et al. detected EGFRvIII in a high proportion of tumors. It is not likely that EGFRvIII mRNA was expressed below the detection level of the assay since; using this method we were readily able to detect expression in positive control MCF-7/EGFRvIII transfected cells as well as in two glioblastoma samples. Furthermore, we were able to detect the expression of EGFRvIII mRNA over a three log range. In the study by Ge et al., a limited amount of tissue prepared by microdissection was extracted and assayed using a nested PCR approach with a 3' mismatch primer. A disadvantage of this approach is that extremely high levels of amplification are required, which could generate non-specific products and may produce false positive results [14]. Unfortunately, samples described in the nested PCR study were not available to make a direct comparison of the two methodologies. However, a direct comparison was made of the non-nested PCR approach using the LCC-6 cell line. Despite our repeated attempts, we were unable to detect EGFRvIII mRNA in this cell line, in contrast to the results published by Lou et al. [13].

Our results show that paraffin embedded tissue samples can be successfully interrogated for mRNA expression by real-time PCR. Recently, this technique was used to measure the levels of 7 reference genes and 185 cancer-related genes in 146 paraffin embedded breast cancer specimens, the details of which have been presented elsewhere [15]. The complete absence of EGFRvIII expression in the cell lines and primary breast cancers was surprising. It is possible that EGFRvIII is expressed at such a low level that it can only be detected by using two rounds of PCR amplification, however, it is not clear what significance this expression may be. Further, others have shown real-time RT-PCR to be superior to nested RT-PCR because it maintains the same level of sensitivity while decreasing the incidence of false-positive results [16].

Our study shows that EGFRvIII mRNA expression is not detectable in any of the investigated breast cancer cell lines or a large number of primary breast cancers. In contrast, the majority of these samples do express EGFRwt at various levels. Given that there is higher expression of EGFRwt, that it has a multitude of ligands and that it can be transactivated in several of ways, it is doubtful that EGFRvIII is a major drive of these breast cancers from the standpoint of the EGFR pathway. From these results, we conclude that EGFRvIII does not play a role in breast cancer and, therefore, does not represent a viable target for therapy. We are now actively examining other tumor types for expression of the EGFRvIII gene product.

\section{Acknowledgements}

This work was supported in part by Breast Cancer Research Foundation grant N003173. The authors 
would like to thank Dr Michael D. Johnson for his critical reading and editing of this manuscript and James C. Stephans, Jenny Y. Wu and Robert Bruce for their technical assistance. We would like to thank Dr Joe W. Gray for the 42 breast cancer RNA samples. The primary breast cancer samples were kindly provided by Dr Jose Esteban from Providence St. Joseph Medical Center, Burbank CA.

\section{References}

1. Carpenter G, Cohen S: Epidermal growth-factor. J Bio Chem 265: 7709-7712, 1990

2. Kim ES, Khuri FR, Herbst RS: Epidermal growth factor receptor biology (IMC-C225). Curr Opin Oncol, 13: 506513, 2001

3. Arteaga CL: The epidermal growth factor receptor: from mutant oncogene in nonhuman cancers to therapeutic target in human neoplasia. J Clin Oncol 19: 32S-40S, 2001

4. Yamazaki H, Fukui Y, Ueyama Y, Tamaoki N, Kawamoto T, Taniguchi S, Shibuya M: Amplification of the structurally and functionally altered epidermal growth-factor receptor gene $(\mathrm{C}-\mathrm{E}$ rbb) in human-brain tumors. Mol Cell Biol 8: 1816-1820, 1988

5. Ekstrand AJ, Sugawa N, James CD, Collins VP: Amplified and rearranged epidermal growth-factor receptor genes in human glioblastomas reveal deletions of sequences encoding portions of the $\mathrm{N}$-terminal and or $\mathrm{C}$-terminal tails. Proc Natl Acad Sci USA 89: 4309-4313, 1992

6. Wong AJ, Ruppert JM, Bigner SH, Grzeschik CH, Humphrey PA, Bigner DS, Vogelstein B: Structural alterations of the epidermal growth-factor receptor gene in human gliomas. Proc Natl Acad Sci USA 89: 2965-2969, 1992

7. Wikstrand CJ, Hale LP, Batra SK, Hill ML, Humphrey PA, Kurpad SN, McLendon RE, Moscatello D, Pegram CN, Reist CJ, Traweek ST, Wong AJ, Zalutsky MR, Bigner DD: Monoclonal-antibodies against EGFRvIII are tumorspecific and react with breast and lung carcinomas and malignant gliomas. Cancer Res 55: 3140-3148, 1995

8. Moscatello DK, Holgadomadruga M, Godwin AK, Ramirez G, Gunn G, Zoltick PW, Biegel JA, Hayes RL, Wong AJ: Frequent expression of a mutant epidermal growth-factor receptor in multiple human tumors. Cancer Res 55: 5536-5539, 1995

9. Ge H, Gong X, Tang CK: Evidence of high incidence of EGFRvIII expression and coexpression with EGFR in human invasive breast cancer by laser capture microdissection and immunohistochemical analysis. Int $\mathbf{J}$ Cancer 98 : 357-361, 2002

10. Jungbluth AA, Stockert E, Huang HJ, Collins VP, Coplan K, Iversen K, Kolb D, Johns TJ, Scott AM, Gullick WJ, Ritter G, Cohen L, Scanlan MJ, Cavanee WK, Old LJ: A monoclonal antibody recognizing human cancers with amplification/overexpression of the human epidermal growth factor receptor. Proc Natl Acad Sci USA 100: 639-644, 2003

11. Tidow N, Boecker A, Schmidt H, Agelopoulos K, Boecker W, Buerger H, Brandt B: Distinct amplification of an untranslated regulatory sequence in the EGFR gene contributes to early steps in breast cancer development. Cancer Res 63: 1172-1178, 2003

12. Tang CK, Gong XQ, Moscatello DK, Wong AJ, Lippman ME: Epidermal growth factor receptor vIII enhances tumorigenicity in human breast cancer. Cancer Res 60 : 3081-3087, 2000

13. Luo X, Gong X, Tang CK: Suppression of EGFRvIIImediated proliferation and tumorigenesis of breast cancer cells by ribozyme. Int J Cancer 104: 716-721, 2003

14. Bustin SA: Absolute quantification of mRNA using realtime reverse transcription polymerase chain reaction assays. J Mol Endo 25: 169-193, 2000

15. Cronin M, Pho M, Dutta D, Stephans JC, Shak S, Kiefer MC, Esteban J, Baker JB: Measurement of gene expression in archival paraffin-embeded tissues: development and performance of a 92 Gene RT-PCR Assay. Am J Path 164(1): 35-42, 2004

16. Morris T, Robertson B, Gallagher M: Rapid reverse transcription-PCR detection of hepatitis $\mathrm{C}$ virus RNA in serum by using the TaqMan fluorogenic detection system. J Clin Micro 34: 2933-2936, 1996

Address for offprints and correspondence: James M. Rae, Ph.D., Division of Hematology and Oncology, Department of Internal Medicine, University of Michigan Medical Center, 5323 Med. Sci. 1, 1150 W. Medical Center Drive, Ann Arbor, MI 481090612, USA; Tel.: + 1-734-764-1460; Fax: + 1-734-615-7019; E-mail: jimmyrae@umich.edu 